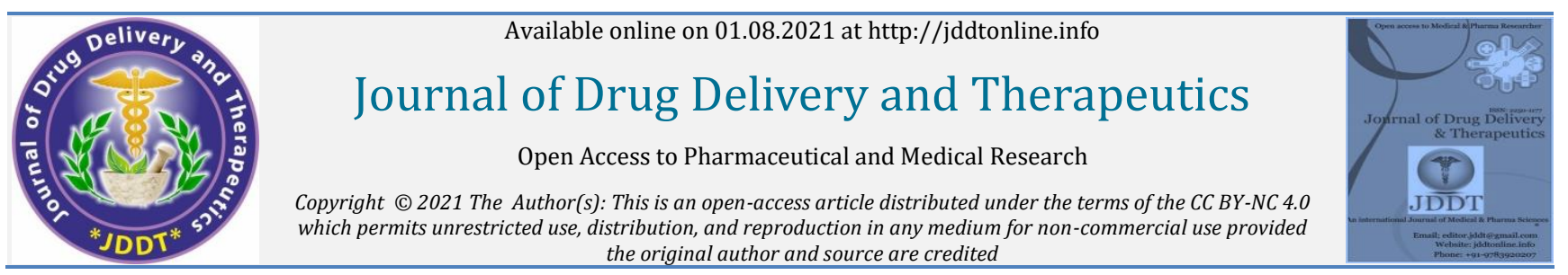

Open Access Full Text Article the original author and source are credited
and

Research Article

\title{
The Knowledge Relationship between Mothers who have Children Aged 2-5 years about Anemia toward Stunting Incidence
}

\author{
Vidi Posdo Simarmata ${ }^{*}$, Wiradi Suryanegara ${ }^{2}$ \\ 1.2 Department of Medical Community, Medical Faculty, Universitas Kristen Indonesia, Jakarta, Indonesia
}

Article Info:

Article History:
Received 11 June 2021
Accepted 23 July 2021

Cite this article as:

Simarmata VP, Suryanegara W, The Knowledge Relationship between Mothers who have Children Aged 2-5 years about Anemia Toward Stunting Incidence, Journal of Drug Delivery and Therapeutics. 2021; 11(4):170-179

DOI: http://dx.doi.org/10.22270/jddt.v11i4.4939

\section{*Address for Correspondence:}

Vidi Posdo Simarmata, Department of Medical Community, Medical Faculty, Universitas Kristen Indonesia, Jakarta, Indonesia

\section{Abstract}

Anaemia is a condition in which there is a decrease in red blood cells or haemoglobin levels in red blood cells caused by several factors such as chronic diseases, iron and folic acid deficiency, or chronic bleeding. Anaemia is one of the world's nutritional problems, especially in developing countries, including Indonesia. According to RISKESDAS 2013, the number of stunting children in Indonesia had reached 37\% (estimated 9 million toddlers) One of the factors that can cause stunting is anaemia during pregnancy. This research aims to determine whether there is a correlation between anaemia-related knowledge of mothers who have children aged 2-5 years old with the incidence of stunting. The research used in the study used analytical research with a cross-sectional method. The data was collected using questionnaires distributed to mothers who have children at the age of 2-5 years in Mekarbakti Village, Sumedang District, West Java. The study results showed that the incidence of stunting is higher in the group of respondents who have better knowledge of anaemia. The conclusion is that there is no correlation between the level of anaemiarelated knowledge of mothers who have children aged 2-5 years with the incidence of stunting in Mekarbakti Village (P Value> 0.05).

Keywords: Anemia, Stunting, Toddler

\section{INTRODUCTION}

Anaemia is a decrease in the number of red blood cells or the level of haemoglobin in red blood cells caused by several factors such as chronic disease, iron and folic acid deficiency, or bleeding. Anaemia is a nutritional problem in the world, especially in developing countries, including Indonesia $\mathbf{1}$. According to RISKESDAS 2018, anaemia in pregnant women increased by 11.8 per cent compared to 2013. The World Health Organization (WHO) states that more than 50 per cent of women worldwide suffer from anaemia. This condition can have a detrimental impact on every age group, including pregnant women ${ }^{2}$.

Stunting is a condition of failure to thrive in children under five due to chronic malnutrition, which can cause children to be short compared to children their age. According to RISKESDAS 2013, the number of stunted children in Indonesia reached $37 \%$ (9 million children under five). One of the factors that can cause stunting is anaemia in the mother during pregnancy 3. Mother's knowledge of the incidence of stunting and the factors that cause it is essential. Based on previous research, an increase in the formal level education of a mother in Indonesia is associated with a low incidence of stunting up to $4.4 \%-5 \%$. The high level of knowledge is closely related to increasing maternal awareness in child development, such as vitamin consumption and iron tablet supplementation during pregnancy, breastfeeding, immunization, and clean living behaviour ${ }^{4}$. Therefore, the authors conducted a study on the relationship between maternal knowledge level about anaemia and the incidence of stunting in Mekarbakti village, Sumedang, West Java. It is, of course, practical and knowing the level of mother's knowledge about anaemia and can be followed up further according to the results obtained.

Based on the description above, the formulation of the problem in this study is conceptualized in the form of questions as follows: a) Is there a relationship between the level of knowledge of mothers who have children aged 2-5 years about anaemia on the incidence of stunting in Mekarbakti village, Sumedang, West Java in 2020?; b) What is the anthropometric picture of children aged 2-5 years in Mekarbakti village, Sumedang, West Java in 2020?; c) How is the distribution of stunted children in Mekarbakti village, Sumedang, West Java according to the mother's final education level?; and d) How is the distribution of stunting children in Mekarbakti village, Sumedang, West Java based on gender?. The objectives of the study: a) to determine the distribution of children aged 2-5 years who experience stunting in Mekarbakti village, Sumedang, West Java; b) to describe the knowledge of mothers who have children aged 2-5 years about anaemia in Mekarbakti village, Sumedang, West Java; c) to determine the distribution of stunting children in Mekarbakti Village, Sumedang, West Java according to the mother's final education level; and d) to 
determine the distribution of stunting children in Mekarbakti Village, Sumedang, West Java by gender.

\section{Literature Revies}

Anaemia is a condition in which haemoglobin $(\mathrm{Hb})$ in the blood is less than usual. The factors that cause iron deficiency anaemia are nutritional status influenced by food pattern, family socioeconomic, environment and health status. The factors behind the high prevalence of iron deficiency anaemia in developing countries are low socioeconomic conditions, including parental education and low income and personal health in a poor environment.

Although various factors cause anaemia, more than $50 \%$ of the most common anaemia cases worldwide are directly caused by a lack of iron intake. In addition, the cause of iron nutritional anaemia is influenced by increased body needs due to chronic disease and blood loss due to menstruation and parasitic (worm) infections. In developing countries such as Indonesia, helminthiasis is still a big problem for cases of iron deficiency anaemia because it is estimated that worms suck $2100 \mathrm{cc}$ of blood every day. Iron deficiency can cause interference or inhibition of growth, both body cells and brain cells 4 .

Lack of Hb levels in the blood can cause lethargy, weakness, fatigue, fatigue and forgetfulness. As a result, it can reduce learning achievement, exercise and work productivity. In addition, iron nutritional anaemia will reduce the body's resistance and lead to infection. Efforts to prevent and control anaemia that has been carried out so far are aimed at pregnant women, while young women at an early age have not been given much attention. So that anaemia can be prevented or overcome, it must consume a lot of foods rich in iron. In addition, the prevention of iron deficiency anaemia can be done by preventing worm infections and giving Fe tablets combined with vitamin $\mathrm{C}$.

Morphologically, anaemia can be classified according to the size of the cells and the haemoglobin they contain, namely: a) Macrocytic - In macrocytic anaemia, the size of red blood cells increases, and the amount of haemoglobin per cell also increases. There are two types of macrocytic anaemia, namely: 1) Megaloblastic anaemia is a deficiency of vitamin B12, folic acid and impaired DNA synthesis; and 2) NonMegaloblastic Anemia is accelerated erythropoiesis and increased membrane surface area; b) Microcytic - Reduced size of red blood cells caused by iron deficiency, impaired synthesis of globin, porphyrin and heme and other iron metabolism disorders; c) Normocytic - In normocytic anaemia the size of red blood cells does not change, this is caused by prolonged blood loss, excessive increase in plasma volume, hemolytic diseases, endocrine, kidney, and liver disorders.

Iron deficiency anaemia - Iron deficiency anaemia is anaemia due to lack of iron in the blood, meaning that the concentration of haemoglobin in the blood is reduced due to disruption of the formation of red blood cells due to lack of iron levels in the blood [6]. If the iron stores in a person's body are deficient, the person is approaching anaemia even though physiological symptoms have not been found Deficient iron stores will gradually not be enough to form red blood cells in the bone marrow so that haemoglobin levels continue to decline below normal limits, and this condition is called iron nutritional anaemia. According to Evatt, iron deficiency anaemia is anaemia caused by reduced body iron stores. This condition is characterized by decreased transferrin saturation, reduced serum ferritin or bone marrow hemosiderin. Morphologically this condition is classified as microcytic-hypochromic anaemia with a quantitative decrease in haemoglobin synthesis 6. Iron deficiency is the leading cause of anaemia. Women of childbearing age often experience anaemia due to blood loss during menstruation and increased iron requirements during pregnancy 7 .

Pathophysiology of Anemia - Iron is required for hematopoiesis (blood formation) and is also required by various enzymes as an activating factor. The iron in enzymes is also needed to transport electrons (cytochromes) to activate oxygen (oxidases and oxygenases). Iron deficiency does not show typical symptoms (asymptomatic) so that anaemia in toddlers is challenging to detect [8]. Signs of nutritional anaemia begin with depletion of iron stores (ferritin) and increased iron absorption, described by increased iron-binding capacity. At a more advanced stage in the form of depletion of iron stores, reduced transferrin saturation reduced amount of protoporphyrin converted to heme, and will be followed by a decrease in serum ferritin levels. Finally, anaemia occurs with its characteristic feature, namely low Hb levels 9 .

When some of the tissue ferritins leave the cells, the serum ferritin concentration is low. Serum ferritin levels can describe the state of iron stores in tissues. Thus, a low serum ferritin level will indicate the person is in a state of nutritional anaemia if the serum ferritin level is $<12 \mathrm{ng} / \mathrm{ml}$. Note that normal serum ferritin levels do not always indicate normal iron status because the reduced iron status is first followed by ferritin levels $\mathbf{1 0}$.

A screening test determines the diagnosis of nutritional anaemia by measuring $\mathrm{Hb}$ levels, hematocrit $(\mathrm{Ht})$, red blood cell volume, $\mathrm{Hb}$ concentration in red blood cells with the lowest limit of $95 \%$ reference 11 . The causes of iron deficiency anaemia are iron intake, iron absorption, loss of iron and increased need. Low iron intake often occurs in people who consume less diverse foods with a diet consisting of rice, beans and a small amount of meat, poultry, fish which are sources of iron deficiency. Iron deficiency disorders often occur due to the wrong food composition both in quantity and quality caused by lack of food supply, poor food distribution, lousy eating habits, poverty and ignorance. A diet rich in iron does not guarantee iron availability in the body because the amount of iron absorbed is highly dependent on the type of iron and food ingredients that can inhibit and increase iron absorption. The need for iron will increase during the growth period, such as in infants, children, adolescents, pregnancy and lactation. Iron requirements are also increased in chronic bleeding caused by parasites. Loss of iron through the digestive tract, skin and urine is called basal iron loss. In women, in addition to basal iron loss, iron loss also occurs through menstruation. In addition, the iron loss is caused by bleeding by worm infection in the intestine $\mathbf{1 2}$.

The effects that are detrimental to health in individuals suffering from iron deficiency anaemia are: a) For infants and children (0-9 years): 1) Impaired motor development and coordination; 2) Developmental disorders and learning abilities; 3) Psychological and behavioural disorders, b) Adolescents (10-19 years): 1) Impaired learning abilities; 2) Decreased ability to work and physical activity; 3) Negative impact on the body's defence system against infectious diseases; 4) Adult men and women; e) Decrease in physical work and income; 5) Decreased resistance to fatigue, and c) Pregnant women: 1) Increased maternal morbidity and mortality; 2) Increased morbidity and mortality of the fetus; 3) Increased risk of low birth weight fetuses ${ }^{13}$.

According to WHO, the limit value of haemoglobin $(\mathrm{Hb})$, which is said to be iron nutritional anaemia for adolescent 
women, is $<12 \mathrm{~g} / \mathrm{dl}$ with serum iron values $<50 \mathrm{mg} / \mathrm{ml}$ and ferritin values $<12 \mathrm{mg} / \mathrm{ml}$. The ferritin value reflects the body's iron reserves to provide an overview of a person's iron status. To determine blood $\mathrm{Hb}$ levels, one of the methods used is the Cyanmethemoglobin method. This method is quite thorough and is recommended by the International Committee for Standardization in Haematology (ICSH). According to this method, the blood is mixed with Drapkin solution to break down haemoglobin into cyanmethemoglobin, and its absorption capacity is then measured at $540 \mathrm{~nm}$ in a photoelectronic calorimeter or spectrophotometer.

The method of determining $\mathrm{Hb}$ that is widely used in Indonesia is Sahli. This method is quite simple in the field, but its accuracy needs to be compared with the standard method recommended by WHO. There are three laboratory tests combined with an examination of $\mathrm{Hb}$ levels so that the results are more precise to determine iron nutritional anaemia. To determine iron nutritional anaemia: Serum Ferritin, Transferrin Saturation, and Free Erythrocyte Protophorph 14. When the level of iron in the blood is less, the circulation of FEB in the blood increases. The average FEB level is $35-50 \mathrm{mg} / \mathrm{dl} \mathrm{RBC}$.

Haemoglobin is the main component of erythrocytes which functions to carry oxygen and carbon dioxide. The red colour of blood is caused by the content of haemoglobin ( $\mathrm{Hb}), \mathrm{a}$ complex protein composition consisting of proteins, globulins, and a non-protein compound called heme. Heme is composed of a circular compound called porphyrin, whose centre is occupied by iron metal (Fe). So heme is porphyriniron compounds, while haemoglobin is a complex compound between globin and heme ${ }^{15}$.

Efforts made in the prevention and control of anaemia are: a) Supplementation of Fe tablets; b) Fortification of food with iron; c) Changing dietary habits by adding food consumption that facilitates iron absorption, such as adding vitamin C; d) Decreased iron loss by eradicating worms. To prevent and overcome anaemia is to consume tablets of added blood. It has been proven from various studies that iron supplementation can increase haemoglobin levels; e) Treatment of iron deficiency anaemia; and f) Since 1997, the government has pioneered new steps in preventing and overcoming anaemia. One of the options is taking blood supplement tablets. It has been proven from various studies that iron supplements can increase haemoglobin $\mathbf{1 6}$.

To overcome the occurrence of anaemia can be done by increasing the consumption of iron from food. Eat animal foods in sufficient quantities. However, because the price is relatively high, people find it challenging to reach it. Eat a variety of foods with complementary nutrients, including vitamins that can increase iron absorption, such as vitamin C. Increasing the consumption of vitamin $C$ by $25,50,100$, and $250 \mathrm{mg}$ can increase iron absorption by 2, 3, 4 and 5 times. Fresh fruits and vegetables are sources of vitamin $\mathrm{C}$, but $50-80 \%$ of vitamin $C$ will be damaged in cooking. Reduce the consumption of foods that can inhibit iron absorption, such as phytate, phosphate, tannin 17. In addition, iron supplementation is beneficial because it can improve haemoglobin status in a relatively short time. In Indonesia, iron pills commonly used in iron supplementation are ferrous sulfate.

The World Health Organization (WHO) states that more than 50 per cent of women in the world suffer from anaemia. This condition can have a detrimental impact on every age group, including pregnant women. In pregnant women, the incidence of anaemia can cause complications for the mother and the baby it contains, such as life-threatening bleeding, miscarriage, low birth weight (LBW) and premature birth. Other studies also mention that anaemia increases the frequency of complications in pregnancy and childbirth in pregnant women. The risk of maternal mortality increases the rate of prematurity, low birth weight, and perinatal mortality 18; 19. One of the effects of iron deficiency anaemia is premature birth, where it is associated with new problems such as low birth weight, immune response deficiency, and psychological and growth problems. If this continues, then it is correlated with low IQ and learning ability. These things result in low quality of human resources, productivity and economic implications.

The incidence of anaemia in pregnancy is closely related to the knowledge of the pregnant woman about anaemia. The better the respondent's knowledge about anaemia, the lower the risk of developing anaemia. There is a relationship between knowledge level about anaemia and the incidence of anaemia in pregnancy 20 . A relationship between the level of knowledge about anaemia and the incidence of anaemia in pregnant women. It shows that the correlation coefficient results, namely knowledge or cognitive, are essential for forming one's actions. From experience and research, it turns out that behaviour that is realized by knowledge will last longer than behaviour that is not realized by knowledge.

Short Toddler (Stunting) is a nutritional status based on the $\mathrm{PB} / \mathrm{U}$ or $\mathrm{TB} / \mathrm{U}$ index wherein the anthropometric standard for assessing children's nutritional status and the measurement results are in the threshold (Z-Score) $<-2$ SD to $-3 \mathrm{SD}$ ( short/stunted) and <-3 SD (very short/severely stunted). Stunting is a chronic malnutrition problem caused by inadequate nutritional intake for a long time due to feeding that is not following nutritional needs. Stunting can occur when the fetus is still in the womb, and only appears when the child is two years old 21.

Stunting that has occurred if it is not balanced with catch-up growth results in decreased growth. The problem of stunting is a public health problem associated with an increased risk of illness, death and inhibition of both motor and mental growth. Stunting is formed by inadequate growth faltering and catch-up growth, reflecting the inability to achieve optimal growth; this reveals that groups of toddlers born with average weight can experience stunting if the fulfilment of further needs is not met correctly $\mathbf{2 2}$.

The assessment of the nutritional status of children under five is most often carried out using anthropometric assessment. In general, anthropometry relates to various body dimensions and body composition of various ages and nutritional levels. Anthropometry is used to see the imbalance of protein and energy intake. Some anthropometric indices that are often used are weight for age, height for age, weight for height which is expressed by the standard deviation of the unit z (Z-score) ${ }^{23}$. Stunting can be detected when a toddler has been weighed and measured for length or height compared with the standard, and the results are below average. So physically, toddlers will be shorter than toddlers his age. This calculation uses the standard Z score from WHO. Regular, short and very short are nutritional statuses based on the index of body length for age or height for age which is the equivalent of the terms stunted (short) and severely stunted (very short). The following is the classification of stunting nutritional status based on indicators of height per age (TB/U) ${ }^{9}$, 
- Very short

: Zscore $<-3.0$

- Short

: Zscore $<-2.0$ s.d. Zscore -3.0

- Normal

: Zscore -2.0

Furthermore, below is a classification of stunting nutritional status based on TB/U and BB/TB indicators.

- Short-thin : Z-score BH/A <-2.0 and Z-score BW/BH <-2.0

- Short -normal : Z-score BH/A $<-2.0$ and Z-score BW/BH between -2.0 to 2.0

\section{- Short-fat : : Z-score -2.0 to Z-score 2.0.}

Anthropometry comes from the words "Anthropos" (body) and "metros" (measurement), so that anthropometry generally means the size of the human body. From a nutritional point of view, nutritional anthropometry is related to various body dimensions and body composition from various ages and nutritional levels. Body dimensions measured included age, weight, height, upper arm circumference, head circumference, chest circumference, hip circumference and thickness of fat under the skin. Changes in body dimensions can describe the general state of health and well-being of individuals and populations. The body dimensions needed in this study are age and height in order to obtain an anthropometric index of the height based on age 24 .

Maternal factors may be due to poor nutrition during preconception, pregnancy and lactation. In addition, it is also influenced by short maternal stature, infection, early pregnancy, mental health, IUGR and premature delivery, close delivery distance, and hypertension. The home environment can be caused by inadequate stimulation and activity, poor implementation of care, food insecurity, inappropriate food allocation, low education of caregivers.

Poor food quality includes poor micronutrient quality, lack of diversity and intake of food sourced from animal foods, non-nutritive content, and low energy content in complementary foods. Inadequate feeding practices, including infrequent feeding, inadequate feeding during and after illness, too light food consistency, insufficient food quantity, unresponsive feeding 25 . Evidence suggests that greater dietary diversity and food consumption from animal sources is associated with improved linear growth. Recent analyzes have shown that households adopting a diverse diet, including a diet fortified with complementary nutrients, will increase nutritional intake and reduce the risk of stunting.

Problems related to breastfeeding practices include delayed initiation, not implementing exclusive breastfeeding and premature cessation of breastfeeding. A study has shown that delaying the initiation of breastfeeding (Delayed initiation) will increase infant mortality. Exclusive breastfeeding is defined as breastfeeding without any other food or beverage supplementation, either in water, juice, or milk other than breast milk. Indonesian Pediatrician Association recommends exclusive breastfeeding for the first six months to achieve optimal growth and development. After six months, infants receive adequate complementary foods, while breastfeeding is continued until 24 months. Continuous breastfeeding for two years contributes to the intake of essential nutrients in infants.

Some examples of infections often experienced are enteric infections such as diarrhoea, enteropathy, and worms, which can also be caused by respiratory infections, malaria, decreased appetite due to infection, and inflammation. There are several causes of short stature, including normal variations, endocrine diseases, skeletal dysplasia, specific syndromes, chronic diseases and malnutrition. Short stature is divided into two, namely normal variations and pathological conditions. Endocrine abnormalities in the factors that cause stunting are associated with $\mathrm{GH}$ deficiency, IGF-1, hypothyroidism, glucocorticoid excess, diabetes mellitus, diabetes insipidus, rickets hypopostamemia. In another reference, it is said that height is the result of a process of genetic (biological) factors, eating habits (psychological) and the fulfilment of nutritious food in children (social). Endocrine and non-endocrine disorders can cause stunting. The most common causes are non-endocrine disorders, namely chronic infectious diseases, nutritional disorders, gastrointestinal disorders, congenital heart disease and socioeconomic factors.

\section{Methodology}

The type of research used is correlational analytic survey research, with a cross-sectional research design to determine the relationship between knowledge of mothers who have children aged 2-5 years about anaemia on the incidence of stunting in Mekarbakti Village in 2020. The study was conducted in Mekarbakti Village, Sumedang Regency, West Java, from January 28, 2020 - February 1, 2020. The target population in this study is all mothers who have children aged 2-5 years, Sumedang Regency, West Java. The affordable population in this study was mothers with children aged 2-5 years, a total of 572 mothers in Mekarbakti Village, Sumedang Regency, West Java. The number of samples used amounted to 85 samples which were calculated using the Slovin formula, namely:

$$
\begin{aligned}
& \mathbf{n}=\frac{\mathbf{N}}{\mathbf{1 + N \mathbf { e } ^ { \mathbf { 2 } }}} \\
& n=\frac{572}{1+\left(5720(0.1)^{2}\right.} \\
& n=85,1 \\
& n=85 \text { persons }
\end{aligned}
$$

For sampling, a non-probability sampling technique was used by consecutive sampling. All subjects who come and meet the selection criteria are included in the study until the required number of subjects is met. The research data source is primary data obtained from anthropometric measurements in children and filling out questionnaires regarding anaemia by parents who have children aged 2-5 years. This study used: stationery, data recording sheets, questionnaire sheets, and anthropometric tools. Data was collected using questionnaires and anthropometric measurements, which included: a) requesting permission to conduct research; b) explain the aims and objectives of the research; c) taking measurements with anthropometry in children aged 2-5 years, d) recording the measurement results on the data recording sheet; and e) distributing questionnaires to mothers with children aged 2-5 years. Data processing is carried out with a computerized system through editing, coding, data entry, cleaning, and data analysis.

\section{RESULT AND DISCUSSION}

This research was conducted in Mekarbakti Village, Pamulihan District, Sumedang Regency, West Java, in January 2019. This study involved mothers who have children aged 2-5 years. From the research that has been 
carried out, the researchers distributed 85 questionnaires to 85 respondents. Of the 85 respondents, they met the inclusion and exclusion criteria and agreed to participate in this study. Of 85 respondents, $40(47.1 \%)$ children were stunted, and 45 (52.9\%) were not stunted.

Table 1. Number of Respondents who have stunting children

\begin{tabular}{llcccc}
\hline & & Frequency & Per cent & Valid Percent \\
\hline \multirow{2}{*}{ Valid } & Stunting & 40 & 47.1 & 47.1 & 47.1 \\
& Not stunting & 45 & 52.9 & 52.9 & 100.0 \\
\hline & Total & 85 & 100.0 & 100.0 \\
\hline
\end{tabular}

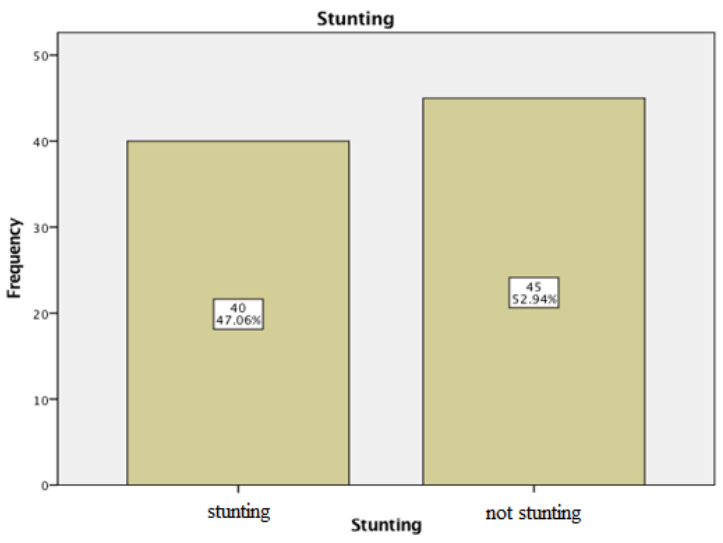

Diagram 1: Number of Respondents who have Stunting Children

Based on the results of the research conducted, it was found that $47.1 \%$ ( 40 respondents) had the last education of junior high school. A total of 30.6\% (26 respondents) had an elementary school education, 20.0\% (17 respondents) had a senior high school education, and 2.4\% ( 2 respondents) had a bachelor's degree.

Table 2: Distribution of Mother's Education Level

\begin{tabular}{llcccc}
\hline & Frequency & Per cent & Valid Percent & Cumulative Percent \\
\hline \multirow{4}{*}{ Valid } & Primary School & 26 & 30.6 & 30.6 & 30.6 \\
& Senior High School & 40 & 47.1 & 47.1 & 77.6 \\
& Junior High School & 17 & 20.0 & 20.0 & 97.6 \\
& Bachelor & 2 & 2.4 & 2.4 & 100.0 \\
\hline
\end{tabular}

Mothers' Education

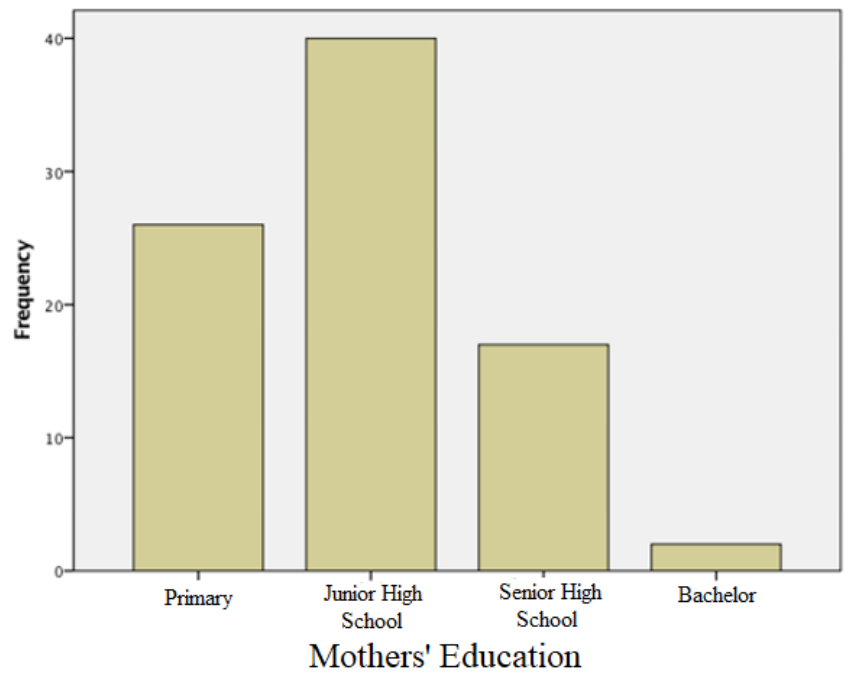

Diagram 2: Distribusi Tingkat Pendidikan Ibu 
Univariate Analysis - The level of knowledge of mothers who have children aged 2-5 years about anaemia in Mekarbakti Village, Pamulihan District, Sumedang, West Java in 2019 The description of the level of knowledge of mothers who have children aged 2-5 years about anaemia is divided into two categories, namely good knowledge and inadequate knowledge.

Table 3: Distribution of Children Aged 2-5 Years who have Stunting Based on Mother's Knowledge Level

\begin{tabular}{llrr}
\hline & & & Mothers' Knowledge \\
\cline { 2 - 4 } Stunting & Stunting & Good & Poor \\
& Not Stunting & 26 & 14 \\
\hline Total & & 28 & 40 \\
\hline
\end{tabular}

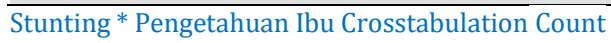

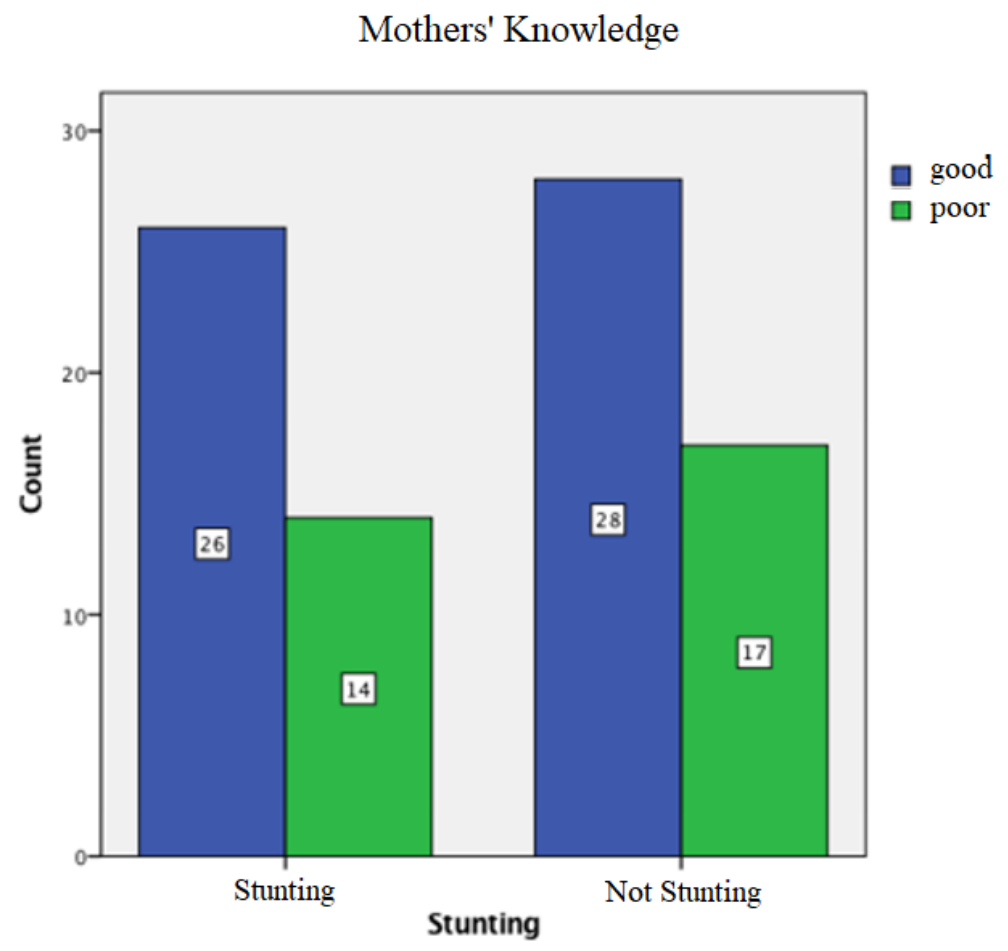

Diagram 3: Distribution of Children Aged 2-5 Years Who Have Stunting Based on Mother's Knowledge Level

Distribution of stunted and non-stunted children aged 2-5 years in Mekarbakti Village, Sumedang, West Java in 2019 The results showed 17 boys (41.4\%) who were stunted and
24 boys (58.5\%) who are not stunted. A total of 23 girls $(52.3 \%)$ were stunted, and 21 girls $(47.7 \%)$ were not stunted.

Table 4: Distribution of Children Aged 2-5 Years who Experience Stunting by Gender

\begin{tabular}{lllll}
\hline & & \multicolumn{2}{c}{ Stunting } \\
\cline { 3 - 5 } & & Stunting & \multicolumn{2}{c}{ Not Stunting } \\
\hline \multirow{2}{*}{ Gender } & Male & 17 & 24 & 41 \\
& Female & 23 & 21 & 44 \\
\hline Total & & 40 & 45 & 85 \\
\hline
\end{tabular}

Jenis Kelamin*Stunting Crosstabulation Count 


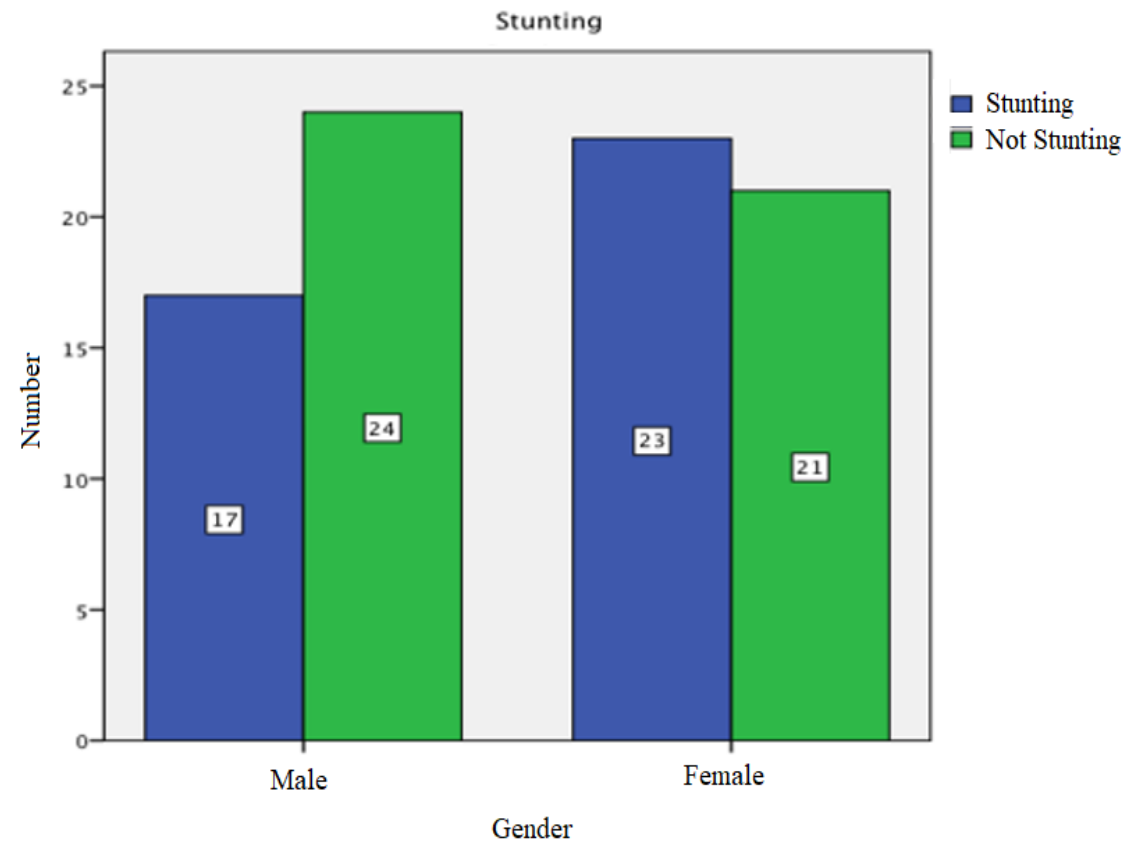

Diagram 4: Distribution of Children 2-5 Years Old with Stunting by Gender

Distribution of stunted and non-stunted children aged 2-5 years based on the mother's last education in Mekarbakti Village, Sumedang, West Java in 2019 - An overview of the educational characteristics of mothers who have children aged 2-5 years who are stunted and not stunted is divided into four categories: Elementary, Middle School, High School and Undergraduate.

Table 5: Distribution of Children Aged 2-5 Years Who Have Stunting Based on Mother's Education Level

\begin{tabular}{lllll}
\hline & & & Stunting & Total \\
& & Stunting & Tidak Stunting & \\
\hline \multirow{3}{*}{ Pendidikan Ibu } & Primary School & 12 & 14 & 26 \\
& Senior High School & 19 & 21 & 40 \\
& Junior High School & 8 & 9 & 17 \\
Total & Bachelor & 1 & 1 & 2 \\
\hline
\end{tabular}

Pendidikan Ibu * Stunting Crosstabulation Count

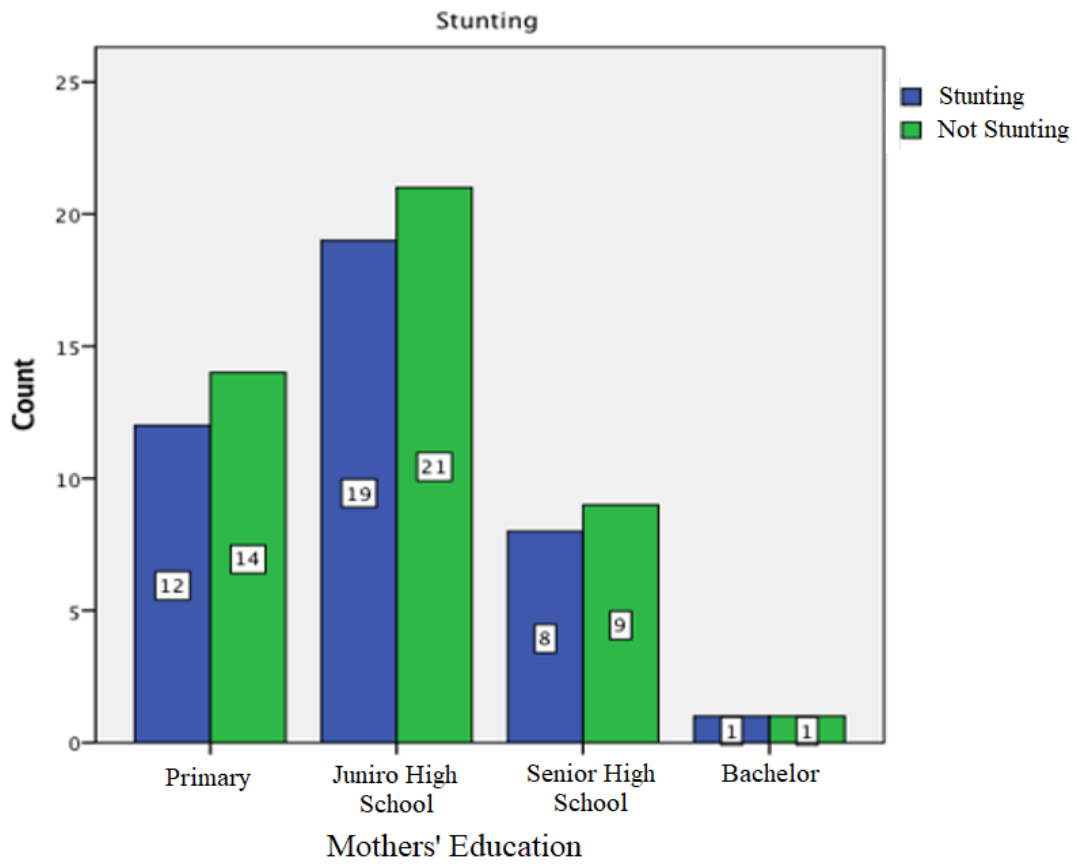

Diagram 5: Distribution of Children 2-5 Years Old with Stunting Based on Mother's Knowledge Level 
Bivariate Analysis - The results of the analysis of the relationship between the level of knowledge of mothers who have children aged 2-5 years about anaemia on the incidence of stunting in Mekarbakti Sumedang Village, West Java in
2019 obtained a P-Value of 0.794 (P-Value $>0.05$ ). So it can be said that the level of knowledge on anaemia does not significantly affect the incidence of stunting.

Table 6: Relationship of Mother's Knowledge Level about Anemia with Stunting Incidence

\begin{tabular}{|c|c|c|c|}
\hline & & P-Score & Stunting \\
\hline \multirow[t]{3}{*}{ P-Score } & Pearson Correlation & 1 & .029 \\
\hline & Sig. (2-tailed) & & .794 \\
\hline & $\mathrm{N}$ & 85 & 85 \\
\hline \multirow[t]{3}{*}{ Stunting } & Pearson Correlation & .029 & 1 \\
\hline & Sig. (2-tailed) & .794 & \\
\hline & $\mathrm{N}$ & 85 & 85 \\
\hline
\end{tabular}

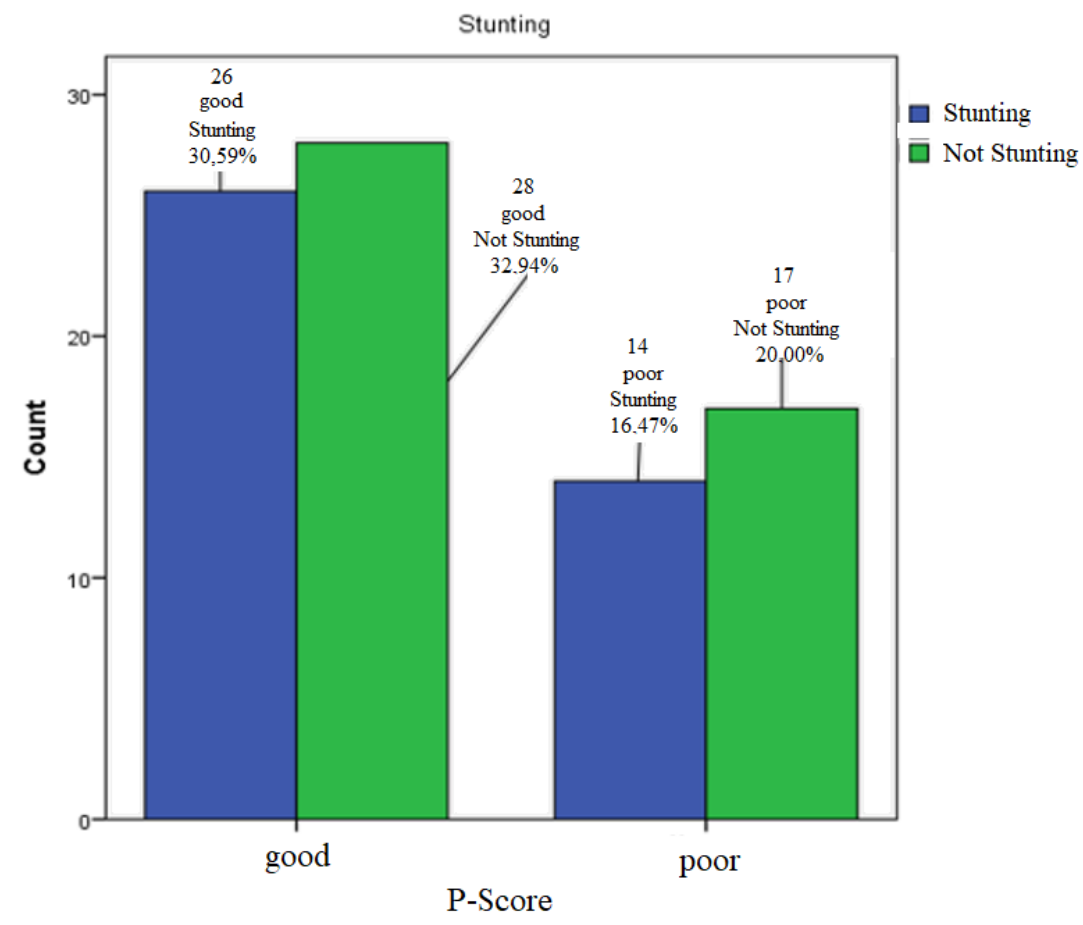

Diagram 6: Relationship of Mother's Knowledge Level about Anemia with Stunting Incidence

Based on the results of research conducted on 85 child respondents aged 2-5 years, it was found that $47.1 \%$ ( 40 respondents) were stunted, and 52.9\% (45 respondents) did not experience stunting. This presentation is higher than the national prevalence of stunting based on the 2013 Riskesdas data, $37.2 \%$. This presentation is also higher than the presentation of stunting globally, which is $22.9 \%$. Characteristics of children aged 2-5 years who are stunted and not stunted by sex - Based on table 7, it is found that the distribution of children aged 2-5 years who are stunted and not stunted by gender. The number of male toddlers was 41 respondents consisting of 17 children (41.4\%) stunting and 24 children under five who were not stunted (58.5\%). Fortyfour respondents under five consist of 23 children (52.3\%) stunting, and 21 children $(47.7 \%)$ were not stunting. Based on the results of this study, the highest stunting rate was found in the female under five. This result is not in line with the results of a study conducted by Wanda Lestari in 2018 in the Asahan district, which stated that the incidence of stunting was more prevalent in men (25 people) 26. However, these study results are in line with research conducted in India in 2018, where the incidence of stunting was higher in women even though in this study, it was said that the incidence of stunting was not related to gender 27 .

Characteristics of children aged 2-5 years who are stunted and not stunted based on the mother's last education - Based on table 8 , it is found that the distribution of children aged 25 years who are stunted and not stunted is based on mother's education. A total of 26 respondents were mothers with elementary school education, consisting of 12 children (46.1\%) stunting and 14 children (53.9\%) not stunting. The last education was junior high school as many as 40 respondents with 19 children (47.5\%) experiencing stunting and 21 children (52.5\%) not experiencing stunting. A total of 17 respondents had a high school education, consisting of 8 children (47\%) stunting and nine children (52\%) not stunting. A total of 2 respondents were mothers with the last education of SI (Bachelor) consisting of 1 child (50\%) stunting and one child (50\%) not stunting. Based on the study results, it was found that the education level of mothers who had the most stunting children was junior high school education. This study is in line with Wanda Lestari et 
al. in 2018, where the results of the highest incidence of stunting occurred in mothers with low education [26]. However, this research is not in line with the research conducted by Rahmawati in 2018 in Jakarta, where the highest incidence of stunting is found in mothers with the latest high education $\mathbf{2 6}$.

The relationship of knowledge of mothers who have children aged 2-5 years about anaemia to the incidence of stunting in Mekarbakti Village, Sumedang, West Java in 2020 - Based on table 9 , there is no significant relationship between the level of knowledge of mothers about anaemia and the incidence of stunting in children aged 2-5 years. It is in line with research conducted in Indonesia which states that anaemia due to iron deficiency does not cause children's growth and development disorders $\mathbf{2 8}$. However, this study is not in line with research conducted in Zimbabwe, which states a significant relationship between knowledge about anaemia and the incidence of stunting because common knowledge of anaemia causes an increase in the incidence of anaemia 29

\section{CONCLUSION}

Based on the results of research conducted on 85 mothers with children aged 2-5 years in Mekarbakti Village, Sumedang Regency, West Java, it was found that 40 respondents had stunted children and 45 respondents had non-stunted children. From these data it can be concluded several things as follows: a) There is no significant relationship between maternal knowledge about anaemia and the incidence of stunting in Mekarbakti Village, Sumedang Regency, West Java; b) Based on the mother's level of knowledge about anaemia, the highest incidence of stunting was found in mothers who had good knowledge of anaemia as many as 26 people (48.1\%) and the highest incidence of non-stunting was in mothers who had good knowledge about anaemia as many as 28 people (62); c) Based on the description of the latest education of mothers who have children aged 2-5 years, the results show that the most stunting children are mothers who have a junior high school education level of 19 people $(47.5 \%)$ and the highest number of non-stunted children are mothers who have a junior high school education level of 21 people $46.7 \%$ ); and d) Based on gender, the highest incidence of stunting was found in the female group of 23 children (52.3\%). Furthermore, the group of children who are not stunted is primarily boys, as many as 24 people (58.5\%).

\section{REFERENCES}

1] Milman, N. Anemia-still a major health problem in many parts of the world!. Annals of hematology, 2011; 90(4):369-377. https://doi.org/10.1007/s00277-010-1144-5

[2] Kaur, K. Anaemia 'a silent killer'among women in India: Present scenario. European Journal of Zoological Research, 2014; 3(1):32-36.

[3] Semba, R. D., de Pee, S., Sun, K., Sari, M., Akhter, N., \& Bloem, M. W Effect of parental formal education on risk of child stunting in Indonesia and Bangladesh: a cross-sectional study. The lancet, 2008; 371(9609):322-328. https://doi.org/10.1016/S01406736(08)60169-5

[4] Moss, W., Darmstadt, G. L., Marsh, D. R., Black, R. E., \& Santosham, M. Research priorities for the reduction of perinatal and neonatal morbidity and mortality in developing country communities. Journal of perinatology, 2002; 22(6):484-495. https://doi.org/10.1038/sj.jp.7210743

[5] Darmawati, D., Tahlil, T., Siregar, T. N., Kamil, H., \& Audina, M. The Implementation of Iron Supplementation and Antenatal Counseling for Iron Deficiency Anemia in Pregnancy. Jurnal Keperawatan Soedirman, 2019; 14(3). https://doi.org/10.20884/1.jks.2019.14.3.859
[6] Zamora, T. G., Guiang, S. F., Widness, J. A., \& Georgieff, M. K. Iron is prioritized to red blood cells over the brain in phlebotomized anemic newborn lambs. Pediatric research, 2016; 79(6):922928. https://doi.org/10.1038/pr.2016.20

[7] Breymann, C., Honegger, C., Holzgreve, W., \& Surbek, D. Diagnosis and treatment of iron-deficiency anaemia during pregnancy and postpartum. Archives of gynecology and obstetrics, 2010; 282(5):577-580. https://doi.org/10.1007/s00404-010-1532-z

[8] Mattiello, V., Schmugge, M., Hengartner, H., von der Weid, N., \& Renella, R. Diagnosis and management of iron deficiency in children with or without anemia: consensus recommendations of the SPOG Pediatric Hematology Working Group. European journal of pediatrics, 2020; 179(4):527-545. https://doi.org/10.1007/s00431-020-03597-5

[9] Shander, A., Javidroozi, M., Naqvi, S., Aregbeyen, O., Çaylan, M., Demir, S., \& Juhl, A. An update on mortality and morbidity in patients with very low postoperative hemoglobin levels who decline blood transfusion (CME). Transfusion, 2014; 54(10pt2):2688-2695. https://doi.org/10.1111/trf.12565

[10] Shattnawi, K. K., Alomari, M. A., Al-Sheyab, N., \& Salameh, A. B. The relationship between plasma ferritin levels and body mass index among adolescents. Scientific reports, 2018; 8(1):1-6. https://doi.org/10.1038/s41598-018-33534-4

[11] Brunken, G. S., França, G. V. A. D., Luiz, R. R., \& Szarfarc, S. C. Agreement assessment between hemoglobin and hematocrit to detect anemia prevalence in children less than 5 years old. Cadernos Saúde Coletiva, 2016; 24(1):118-123. https://doi.org/10.1590/1414-462X201600010x01

[12] Loukas, A., Bethony, J. M., Mendez, S., Fujiwara, R. T., Goud, G. N., Ranjit, N., ... \& Hotez, P. J. Vaccination with recombinant aspartic hemoglobinase reduces parasite load and blood loss after hookworm infection in dogs. PLoS medicine, 2005; 2(10):e295. https://doi.org/10.1371/journal.pmed.0020295

[13] Hameed, A., Karaalp, I. S., Tummala, P. P., Wani, O. R., Canetti, M., Akhter, M. W., ... \& Elkayam, U. The effect of valvular heart disease on maternal and fetal outcome of pregnancy. Journal of the American College of Cardiology, 2001; 37(3):893-899. https://doi.org/10.1016/S0735-1097(00)01198-0

[14] Khaidir, M. Anemia defisiensi besi. Jurnal Kesehatan Masyarakat Andalas, 2007; 2(1):140-145.

[15] Gupta, A., Manaktala, U., \& Rathore, A. M. A randomised controlled trial to compare intravenous iron sucrose and oral iron in treatment of iron deficiency anemia in pregnancy. Indian Journal of Hematology and Blood Transfusion, 2014; 30(2):120125. https://doi.org/10.1007/s12288-012-0224-1

[16] Yi, J., Thomas, L. M., Musayev, F. N., Safo, M. K., \& Richter-Addo, G. B. Crystallographic trapping of heme loss intermediates during the nitrite-induced degradation of human hemoglobin. Biochemistry, 2011; 50(39):8323-8332. https://doi.org/10.1021/bi2009322

[17] Pedlar, C. R., Brugnara, C., Bruinvels, G., \& Burden, R. Iron balance and iron supplementation for the female athlete: a practical approach. European journal of sport science, 2018; 18(2):295-305 https://doi.org/10.1080/17461391.2017.1416178

[18] Haileslassie, H. A., Henry, C. J., \& Tyler, R. T. Impact of household food processing strategies on antinutrient (phytate, tannin and polyphenol) contents of chickpeas (C icer arietinum L.) and beans (P haseolus vulgaris L.): a review. International Journal of Food Science \& Technology, 2016; 51(9):1947-1957. https://doi.org/10.1111/ijfs.13166

[19] Guzel, A. I., Kuyumcuoglu, U., \& Celik, Y. Are maternal and fetal parameters related to perinatal mortality in HELLP syndrome?. Archives of gynecology and obstetrics, 2011; 283(6):1227-1232. https://doi.org/10.1007/s00404-010-1534-x

[20] Baby, A., Venugopal, J., D'silva, R., Chacko, S., Vineesha, P. V., \& Kumary, T. V. Knowledge on management of anemia during pregnancy: a descriptive study. Archives of Medicine and Health 
Sciences, 2014; 2(2):140. https://doi.org/10.4103/23214848.144308

[21] Titaley, C. R., Ariawan, I., Hapsari, D., Muasyaroh, A., \& Dibley, M. J. Determinants of the stunting of children under two years old in Indonesia: a multilevel analysis of the 2013 Indonesia basic health survey. Nutrients, 2019; 11(5):1106. https://doi.org/10.3390/nu11051106

[22] Gough, E. K. (2015). Linear Growth Faltering in Infants in Lowand Middle-Income Countries: The Intestinal Microbiota, the Role of Antibiotics, and the Timing of Linear Growth Failure. McGill University (Canada).

[23] Stephens, K., Escobar, A., Jennison, E. N., Vaughn, L., Sullivan, R., Abdel-Rahman, S., \& CMH Nutrition Services Z-Score Research Team. Evaluating mid-upper arm circumference z-score as a determinant of nutrition status. Nutrition in Clinical Practice, 2018; 33(1):124-132. https://doi.org/10.1002/ncp.10018

[24] Martin-Calvo, N., Moreno-Galarraga, L., \& Martinez-Gonzalez, M. A. Association between body mass index, waist-to-height ratio and adiposity in children: a systematic review and metaanalysis. Nutrients, 2016; 8(8):512. https://doi.org/10.3390/nu8080512
[25] Kulwa, K. (2016). Dietary strategies to improve feeding practices, dietary adequacy and growth of infants and young children in rural Tanzania (Doctoral dissertation, Ghent University).

[26] Lestari, W., Rezeki, S. H. I., Siregar, D. M., \& Manggabarani, S. Factors related to the incidence of stunting in public elementary school children 014610 Sei Renggas, Kisaran Barat District, Asahan Regency. Jurnal Dunia Gizi, 2018; 1(1):59-64. https://doi.org/10.33085/jdg.v1i1.2926

[27] Rahmawati, R., Tanziha, I., Hardinsyah, H., \& Briawan, D. Prevalence and Risk Factors for Late Adolescent Stunting. Window of Health, 1(2):90-96. https://doi.org/10.33368/woh.v0i0.31

[28] Singh, R., Rao, S., Charlette, L., Thatkar, P. V., Rajaram, N., \& Sethuraman, A. R. (2018). Socio-demographic correlates of stunting among children in Port Blair, India. International Journal of Community Medicine and Public Health, ; 5(10):4231. https://doi.org/10.18203/2394-6040.ijcmph20183838

[29] Kabir, Y., Shahjalal, H. M., Saleh, F., \& Obaid, W. Dietary pattern, nutritional status, anaemia and anaemia-related knowledge in urban adolescent college girls of Bangladesh. JPMA. The Journal of the Pakistan Medical Association, 2010; 60(8):633. 